\title{
Active and latent tuberculosis in refugees and asylum seekers: a systematic review and meta-analysis
}

Raquel Proença', Fernanda Mattos Souza', Mayara Lisboa Bastos', Rosângela Caetano ${ }^{1}$, José Ueleres Braga ${ }^{1,2}$, Eduardo Faerstein ${ }^{1}$ and Anete Trajman ${ }^{1,3,4^{*}}$ (D)

\begin{abstract}
Background: In 2018, there were 70.8 million refugees, asylum seekers and persons displaced by wars and conflicts worldwide. Many of these individuals face a high risk for tuberculosis in their country of origin, which may be accentuated by adverse conditions endured during their journey. We summarised the prevalence of active and latent tuberculosis infection in refugees and asylum seekers through a systematic literature review and metaanalyses by country of origin and host continent.
\end{abstract}

Methods: Articles published in Medline, EMBASE, Web of Science and LILACS from January 2000 to August 2017 were searched for, without language restriction. Two independent authors performed the study selection, data extraction and quality assessment. Random effect models were used to estimate average measures of active and latent tuberculosis prevalence. Sub-group meta-analyses were performed according to country of origin and host continent.

Results: Sixty-seven out of 767 identified articles were included, of which 16 entered the meta-analyses. Average prevalence of active and latent tuberculosis was 1331 per 100 thousand inhabitants [95\% confidence interval $(\mathrm{Cl})=$ $542-2384]$ and $37 \%(95 \% \mathrm{Cl}=23-52 \%)$, respectively, both with high level of heterogeneity (variation in estimative attributable to heterogeneity $\left[1^{2}\right]=98.2$ and $99.8 \%$ ). Prevalence varied more according to countries of origin than host continent. Ninety-one per cent of studies reported routine screening of recently arrived immigrants in the host country; two-thirds confirmed tuberculosis bacteriologically. Many studies failed to provide relevant information.

Conclusion: Tuberculosis is a major health problem among refugees and asylum seekers and should be given special attention in any host continent. To protect this vulnerable population, ensuring access to healthcare for early detection for prevention and treatment of the disease is essential.

Keywords: Forced migration, Mycobacterium tuberculosis, Latent tuberculosis infection, Prevalence, Global health

\footnotetext{
*Correspondence: atrajman@gmail.com

${ }^{1}$ State University of Rio de Janeiro, Rio de Janeiro, RJ, Brazil

${ }^{3}$ McGill University, Montreal, QC, Canada

Full list of author information is available at the end of the article
}

C C The Author(s). 2020 Open Access This article is licensed under a Creative Commons Attribution 4.0 International License, which permits use, sharing, adaptation, distribution and reproduction in any medium or format, as long as you give appropriate credit to the original author(s) and the source, provide a link to the Creative Commons licence, and indicate if changes were made. The images or other third party material in this article are included in the article's Creative Commons licence, unless indicated otherwise in a credit line to the material. If material is not included in the article's Creative Commons licence and your intended use is not permitted by statutory regulation or exceeds the permitted use, you will need to obtain permission directly from the copyright holder. To view a copy of this licence, visit http://creativecommons.org/licenses/by/4.0/. The Creative Commons Public Domain Dedication waiver (http://creativecommons.org/publicdomain/zero/1.0/) applies to the data made available in this article, unless otherwise stated in a credit line to the data. 


\section{Background}

In 2018, there were 70.8 million refugees, asylum seekers and displaced persons worldwide, the largest number ever recorded [1]. A refugee is someone who "owing to well-founded fear of being persecuted for reasons of race, religion, nationality, membership of a particular social group or political opinion, is outside the country of his nationality and is unable or, owing to such fear, is unwilling to avail himself of the protection of that country" [2]. Asylum seekers are persons who claim to be admitted to a country as refugees and are awaiting the authorities' decision [3].

Refugees and asylum seekers may have a significant burden of infectious diseases, such as tuberculosis, malaria, viral hepatitis and parasitic infections, as a result of the prevalence of such diseases in their country of origin and of exposure to adverse conditions during migration and after arrival at the host country [4-7]. They usually come from countries where different communicable diseases are endemic and often received minimal medical care prior to departure $[8,9]$. In addition, confinement for years in conditions of overcrowding and insalubrity in shelters, rural camps or urban slums make them highly vulnerable to communicable diseases [10-12].

Tuberculosis is a major cause of human mortality globally [13]. Mycobacterium tuberculosis infects $23 \%$ of the global population, [14] and in the absence of treatment for latent M. tuberculosis infection (LTBI), 5 to $10 \%$ of these individuals can develop active tuberculosis, most within 2 years of infection [15]. Risk of progression from LTBI to active disease among migrants is higher throughout their journey and may last longer after arrival in host countries $[16,17]$. Effective treatment of LTBI can reduce up to $90 \%$ the risk of progression to active tuberculosis, and is considered now a major action to eliminate the disease by 2050 , as proposed by the End Tuberculosis Strategy [18].

Refugees, asylum seekers and internally displaced migrants live in heterogeneous socio-economic conditions and have various origins, reasons for fleeing and legal status. Yet, overall, compared with other categories of immigrants, they may be at higher risk for tuberculosis either having arrived with active tuberculosis in the destination country, or from developing active tuberculosis from previous LTBI or from acquiring the disease upon arrival $[19,20]$. The debatable "healthy migrant effect" may not apply to this highly vulnerable population [21].

A previously published systematic review [20] has analysed the prevalence of tuberculosis among all immigrants and summarised data from 1980 to 2004, before the more recent migratory crisis. Additionally, a narrative review on infectious diseases in refugees was published, with data on active and latent tuberculosis from 29 articles from 2010 to 2016 [22]. Other reviews have also been published on refugees in specific scenarios, such as the effectiveness and coverage of tuberculosis screening in Europe [23, 24], tuberculosis in refugee camps [17], yield of screening for active tuberculosis in Germany [25], and prevalence of tuberculosis in the United Kingdom [26]. To our knowledge, no systematic review on active and latent tuberculosis prevalence in refugees is available. The current study aimed to summarise the prevalence of LTBI and active tuberculosis in refugees and asylum seekers, despite their high heterogeneity as a population.

\section{Methods}

\section{Search strategy}

We searched the bibliographic databases MEDLINE, EMBASE, LILACS and Web of Science, using the terms "tuberculosis", "prevalence", "refugee", "asylum seekers", "forced migration", as MesH terms and text word. Strategy searches are available in the supplement material (Table S1 and S2).

The search was conducted in August 2017, without language or other restrictions. Studies published between January 2000 and August 2017 were eligible in order to contemplate the recent immigration crisis. The cut-off for the initial date was based on the trend of numbers of manuscripts published (Figure S1). We also searched the lists of references of the included studies, reviews and government reports.

\section{Study selection}

The study selection, data extraction and quality assessment of studies were carried out by two independent reviewers (RP and FMS). Disagreements were solved by consensus or by two other reviewers (AT and MB). In addition, a $10 \%$ sample of the excluded studies was examined by reviewers $\mathrm{AT}$ and $\mathrm{MB}$.

Reference data were stored in the EndNote web reference manager [Thomson Reuters (SCIENTIFIC), NYC, USA], and duplicate references were discarded. The selection was performed in two steps: screening of titles and abstracts, and full text evaluation. Although the search did not restrict language, only studies wrtitten in English, French, Spanish or Portuguese were included in the following steps. All studies on active tuberculosis or LTBI in the targeted population were included if the estimation of prevalence was reported or data were available for its calculation. Studies including mixed populations, i.e., not exclusively refugees and asylum seekers were also included if prevalence could be extracted by stratum

There were no restrictions on the tuberculosis clinical characteristics (pulmonary or extrapulmonary, drug susceptible or resistant) or study population (as to sex, age or country of origin and host continent). Cross- 
sectional, cohort studies and clinical trials were eligible. We restricted the selection to studies with at least 30 individuals.

For the diagnosis of active tuberculosis, smear microscopy, culture or molecular tests (Xpert ${ }^{\circ} \mathrm{MTB} / \mathrm{RIF}$ and others), as well as clinical and radiological criteria, were accepted. For the diagnosis of LTBI, tuberculin skin testing (TST) or interferon-gamma release assays (IGRA) were accepted, and the presence of LTBI was considered if any of the two tests was positive [27]. We followed TST cut-off points for LTBI definition used by the study authors.

\section{Data collection process}

Data extraction was conducted using an electronic form built on the EpiData 3.1 software (Epidata Association, Odense, Denmark). Whenever available, information on the number of individuals, events of interest and prevalence rates was collected by country of origin and host continent, to perform subgroup analyses. Studies with inpatients were classified as "hospitalised populations". If the study was carried out in a hospital with outpatients, participants were not classified as hospitalised.

\section{Methodological quality of studies}

Quality assessment of studies was carried out by two independent reviewers (RP and FMS) based on the document "Strengthening the Reporting of Observational Studies in Epidemiology" (STROBE) [28]. Differences were resolved by consensus. High quality was defined as at least $80 \%$ of STROBE criteria fulfilled, average quality as $50-79 \%$ of criteria were fulfilled and low quality as less than $50 \%$ of criteria fulfilled. Additionally, nonbacteriologically confirmed diagnosis of tuberculosis was considered to increase the risk of information bias, and non-routine screening was considered to increase the risk of selection bias. All studies that reported the necessary information (i.e., country of origin or host continent) were included in the meta-analyses, regardless of their quality.

\section{Data analyses}

Study characteristics, population profile, setting and methodological aspects were described using frequency tables. Refugees and asylum seekers constitute a highly heterogeneous group of people, depending not only on individual cultural and socio-economic characteristics, but also on the reasons for fleeing their country and their legal status in the host country. We hypothesised that origin and destination could influence the prevalence of active tuberculosis and LTBI and thus opted to perform a meta-analysis by country of origin and a subgroup analysis by continent of destination. For these analyses, we used the studies that contained this information. Average prevalence rates and their 95\% confidence intervals $(\mathrm{CI})$ were estimated using a random effect model. Freeman-Tukey transformation was used to stabilise variance measures. Heterogeneity analysis was performed using variation in estimative attributable to heterogeneity $\left(\mathrm{I}^{2}\right)$ statistics and Q chi-square test. All statistical analysis and Forest plots were performed using the STATA 13 software (module metaprop) (StataCorp LP, College Station, USA) [29].

The Preferred Reporting Items for Systematic Reviews and Meta-Analyses (PRISMA) [30] was used for reporting. A filled PRISMA form for this manuscript is available in the supplementary material (Chart S1). The full review protocol is available in PROSPERO, registration number CDR42016052361.

\section{Results}

We identified 767 references, of which 282 were duplicated and thus excluded. After reading the titles and abstracts of the 485 studies, 170 were selected for full text reading. For abstract selection, initial agreement between the two main reviewers was $88 \%$. In the $10 \%$ sample selected for check by the two additional reviewers, initial agreement was $93 \%$. For full texts, initial agreement between the two main reviewers was $85 \%$. In the $10 \%$ sample checked by the two additional reviewers, initial agreement was $80 \%$. Final consensus was obtained in $100 \%$ of them.

Sixty-seven studies were included in the present review. Reasons for exclusion of the other 103 studies are displayed in Fig. 1. Information on countries of origin and host continent was available in 16 studies, which were included in the meta-analyses.

Sixty-six studies were published in English and one in French [31]. Fifteen studies reported active tuberculosis prevalence, 21 reported LTBI prevalence and 31 reported both. The total screened population was 599,072.

\section{Active tuberculosis prevalence Study characteristics and population}

Among the 46 studies that reported active tuberculosis prevalence, $56.5 \%$ were cross-sectional; none were clinical trials (Table 1). Two thirds of these studies were published after 2009, and among them, half completed data collection before 2011. Sixty-three per cent of studies included over 500 people.

The total of individuals screened for active tuberculosis was 537,218 , with a single study evaluating 232,738 individuals. Eighty-one per cent of studies were conducted in refugees $(n=437,264), 18 \%$ in asylum seekers $(n=95,283)$, and $0.9 \%$ in both $(n=4671)$.

The mean age, reported by $33 \%$ of studies $[4,10,35$, $39,41,50-52,54,55,57,62,68,69,71]$, ranged from 18 to 40.7 years. Prevalence by sex was reported by only $17 \%$ of the studies. 


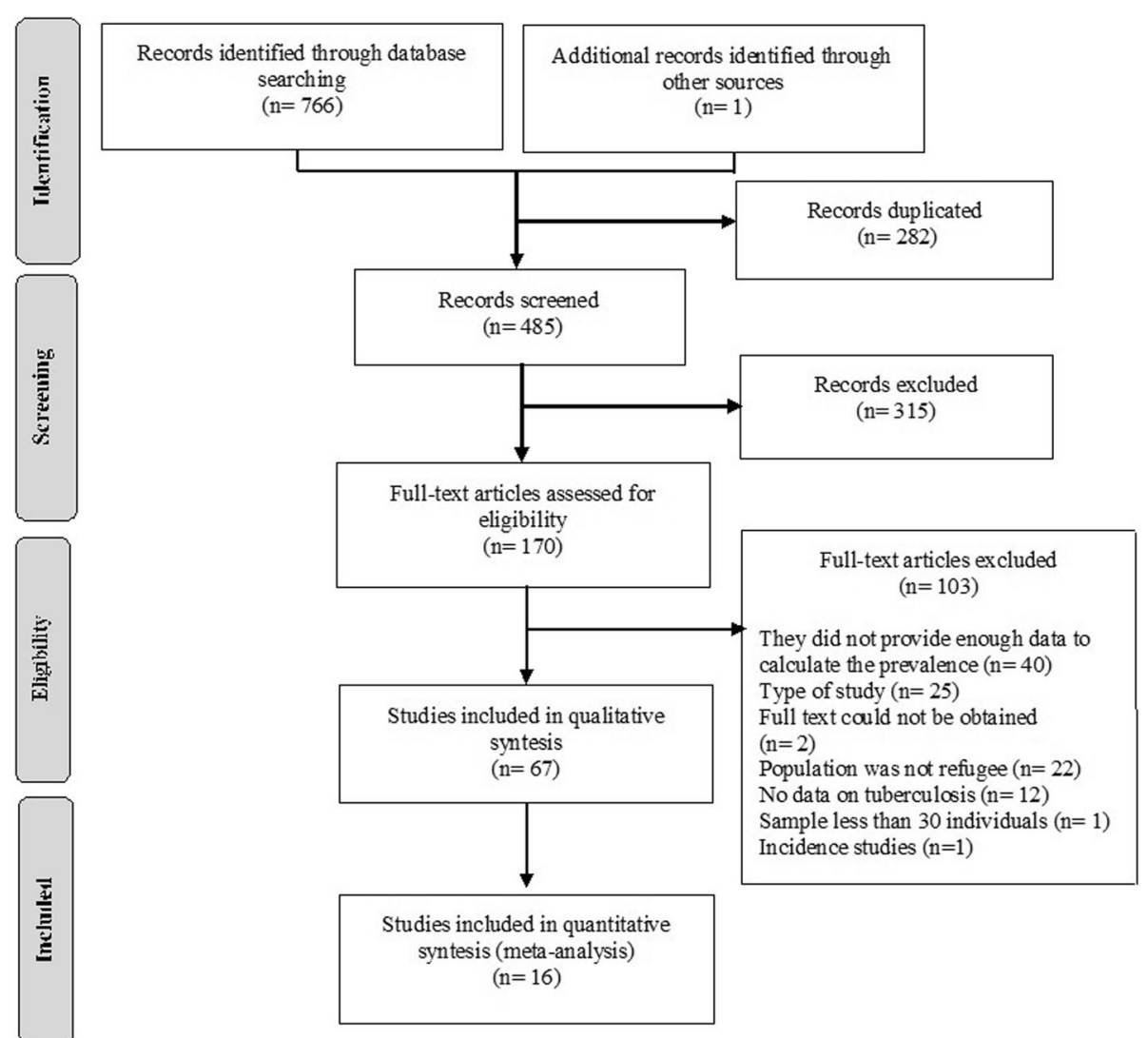

Fig. 1 Flowchart showing inclusions and exclusions from the systematic review

The average time since arrival of refugees and asylum seekers to the host country to the time of evaluation for tuberculosis was 3.9 months (ranging from 0.7 to 12.8 months) in the $9 \%$ of studies $[53,64,65,73]$ conveying this information.

Sixty-seven (31/46) per cent of studies concomitantly evaluated the presence of LTBI in their populations. Among these, 57\% used the LTBI diagnostic as a prerequisite to investigate the presence of active tuberculosis. In other words, they performed a diagnostic test for LTBI with TST or IGRA to rule out active tuberculosis; if they were positive, a chest X-ray was also performed and if it was indicative of active tuberculosis, bacteriological tests were conducted. Otherwise, TST or IGRA-positive individuals were considered to have LTBI.

\section{Main findings}

Active tuberculosis prevalence rates varied from 0 to 11 , 364 per 100 thousand inhabitants, with $89 \%$ of studies reporting values less than 5000 per 100 thousand. Considering studies that reported the prevalence by country of origin, the average prevalence of active tuberculosis was 1331/100 thousand inhabitants (95\% CI, 542-2384), with high heterogeneity ( $\mathrm{I}^{2}=98 \%$, Fig. 2 ). The prevalence was higher among refugees from Syria $(11,364 / 100$ thousand inhabitants, 95\% CI, 3794-24,558), observed in a single study with 44 hospitalised participants. Studies with individuals from Ethiopia, Ghana and Tunisia had results with large confidence intervals, in samples smaller than 100 persons $[10,53]$.

With regards to the host continent, refugees who immigrated to Europe, Asia and America presented a similar average prevalence of 1458, 860 and 1080 per 100 thousand inhabitants, respectively (Fig. 3). Europe was the continent that received refugees from the most diverse nationalities, better allowing an assessment of heterogeneity. In the other continents, this individual evaluation was not possible due to the small numbers. Refugees from Eritrea, Ethiopia and Somalia immigrated to Europe $[10,53]$ in the three studies that contained this information, and had a slightly larger tuberculosis prevalence. More information about the meta-analyses data on active tuberculosis can be found on the supplement material (Table S3).

\section{LTBI prevalence}

Study characteristics and population

Fifty-four per cent of the 52 studies that reported LTBI prevalence were cohort studies; there were no clinical trials (Table 2). Sixty per cent of studies were published 


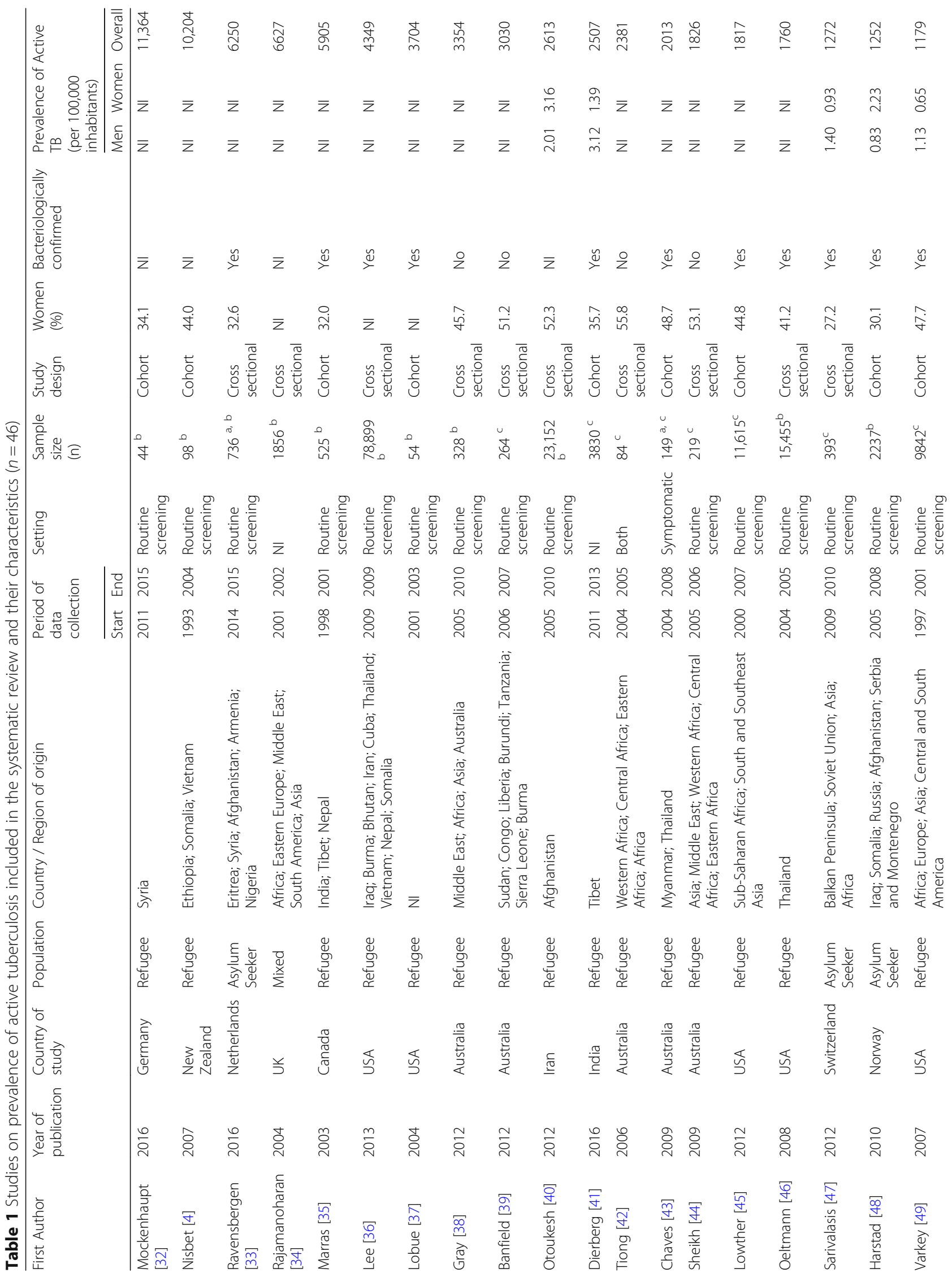




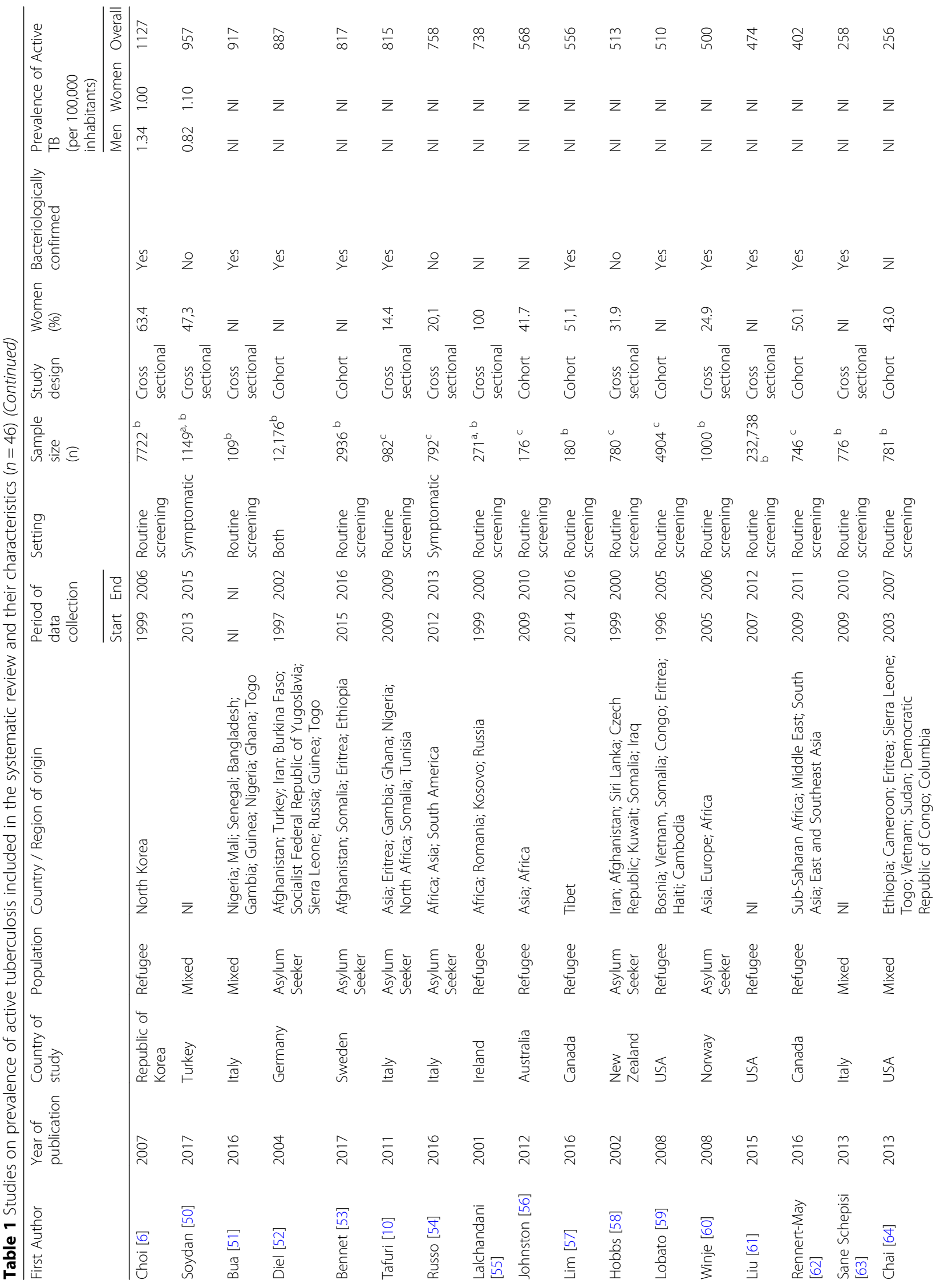




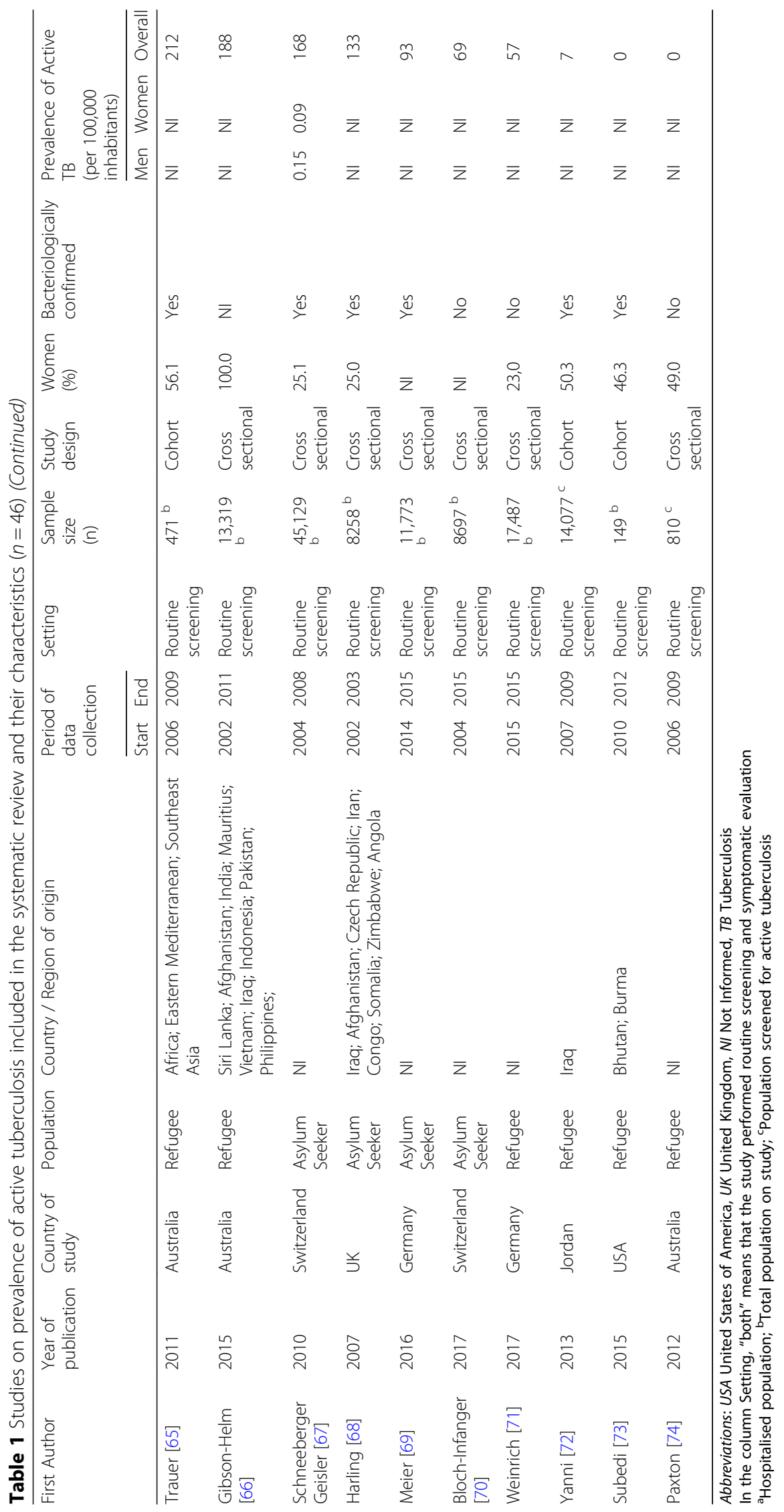




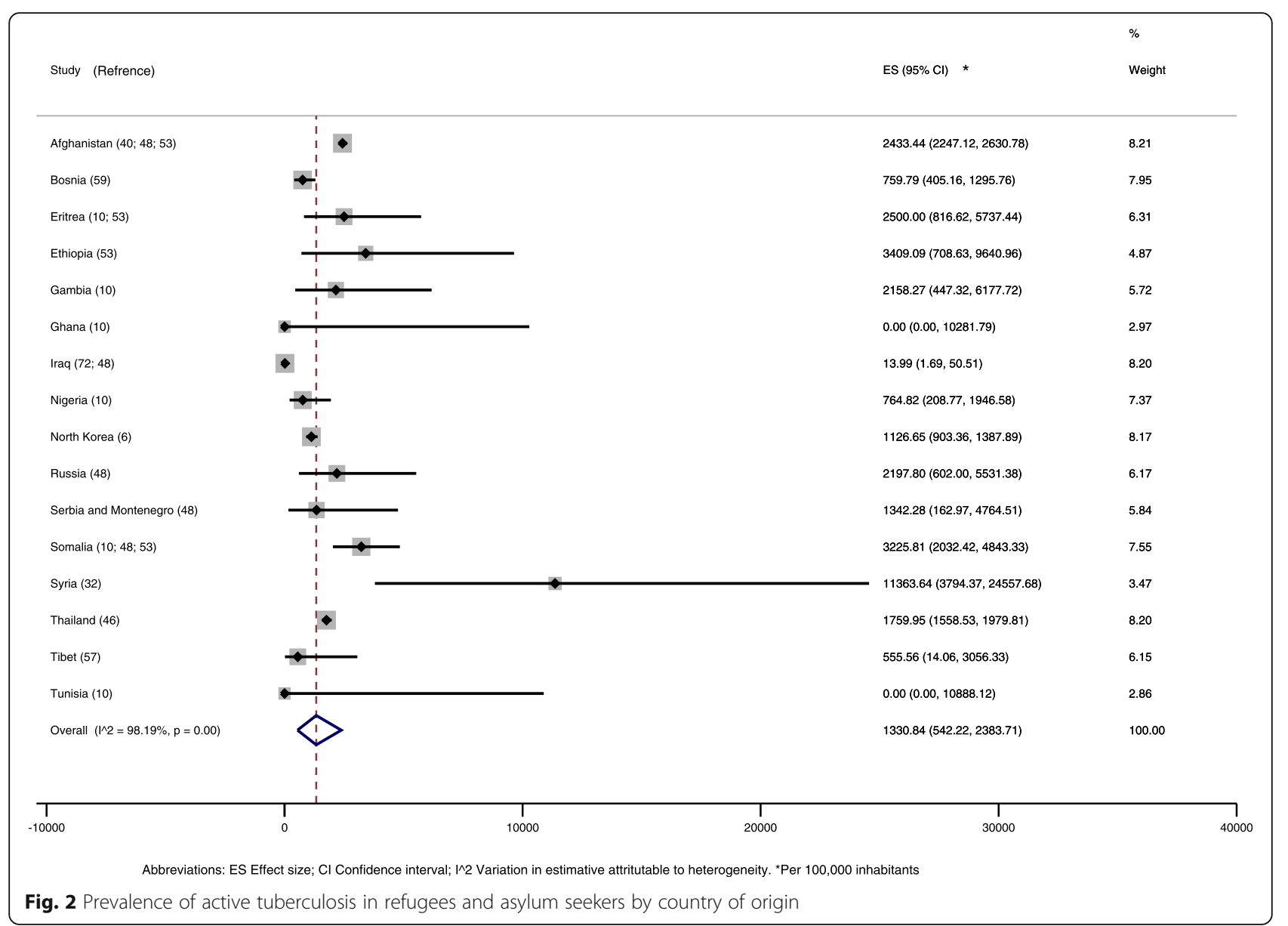

after 2009, and among them half completed data collection before 2011; one study did not provide this information. Thirty-one studies included over 500 participants.

A total of 271,544 individuals were screened for LTBI: 233,688 individuals were refugees (reported by $67 \%$ of studies) and 27,960 individuals were asylum seekers (reported by $21 \%$ of studies). The remaining were studies including both types of situations.

The mean age, reported by $33 \%$ of studies $[4,10,31$, $35,39,51,52,57,62,68,77,78,83,84,88,93,94]$, ranged from 3.5 to 39 years, with the lowest prevalence in a study that included only children (mean age 3.5 years). Only $21 \%$ of studies reported the prevalence by gender.

The average time since arrival of refugees and asylum seekers to the host country at the time of evaluation for LTBI was 3.8 months (range: 0.7-12.8 months) among the $13 \%$ of studies that reported this information [53, 64, $65,73,75,82,91]$.

Eighty-nine per cent of studies performed TST and $77 \%$ of those reported the TST cut-off point used to define LTBI: $10 \mathrm{~mm}$ was used in $78 \%$ of studies. Some studies considered different cut-off points to different populations (children, human immunodeficiency virus (HIV)-infected or BCG-vaccinated individuals).

\section{Main findings}

Prevalence of LTBI ranged from 0.4 to $81.5 \%$, with $61 \%$ of the studies reporting a prevalence rate higher than $30 \%$.

In the meta-analysis by country of origin, prevalence rates were highly heterogeneous (I2 $=99.8 \%)$, with an average measure of $37 \%$ (95\% CI, 23-52) (Fig. 4). Refugees from Cuba and Iraq presented the lowest rates, 0.4 and 5\% respectively, and from North Korea, the highest rate, $81 \%$, systematically screened when arriving in South Korea [6]. Targeted populations and sample sizes varied largely, with the Cuban study [94] evaluating 241 children under 7 years of age (and finding one LTBI case) and large systematic screening for active tuberculosis of Iraq refugees $[72,91]$ applying for visa or recently arrived in the United States of America (USA). Small sample sizes eventually resulted in very wide confidence intervals [10]. 


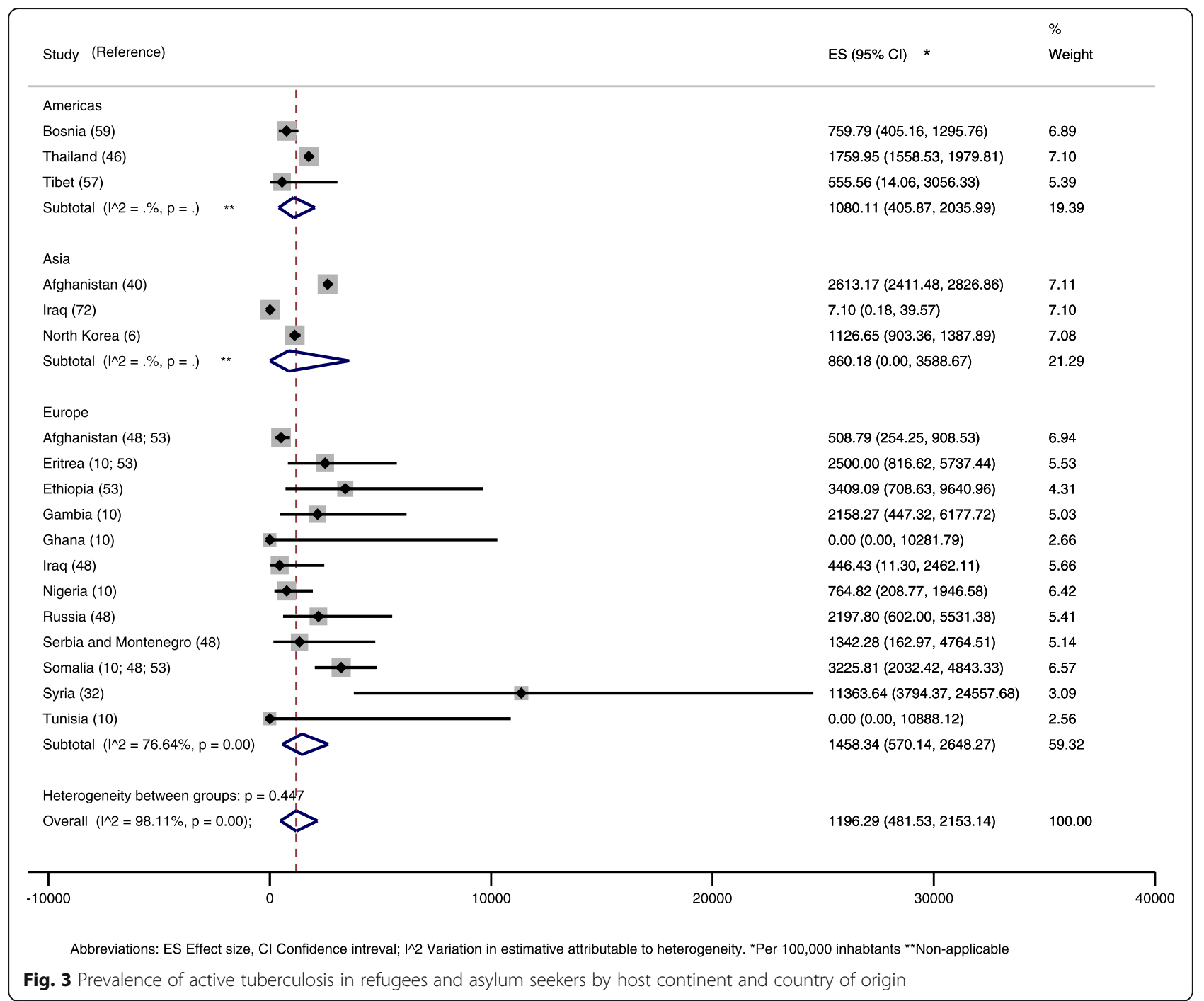

In the subgroup analysis by host continent, refugees who immigrated to Europe presented the highest prevalence (41, 95\% CI, 20-65), followed by those who went to the Americas (28, 95\% CI, 18-40) (Fig. 5). However, one study in the USA excluded individuals with immunosuppressive conditions and thus had a high risk of false negative results [75]. Somali refugees who went to America had a higher prevalence rate (54\%) than those who went to Europe (38\%), while Iraq refugees who went to the Americas had a higher prevalence rate (14\%) than those who went to Asia (2\%). Overall, there were very few studies with information on country of origin and host continent. More information about the metaanalyses data on LTBI can be found on the supplement material (Table S4).

\section{Quality of studies and risk of bias}

None of the 65 studies fulfilled all quality criteria. Among the 33 cross-sectional and the 32 cohort studies, only 13 and 11 respectively were considered high quality (Figure S2 and S3); 14 and 18 studies were of medium quality; and 6 cohort and 3 cross-sectional studies were considered low quality. Two studies $[36,91]$ were organization reports; it was not possible to perform the quality assessment.

In $85 \%$ of studies $(n=569,880)$, routine screening of all the individuals who arrived in the host country was the reason for the enrollment and $9 \%$ of studies tested individuals who sought health service with symptoms $(n=11,234)$. Only one study was conducted in refugee camps [46] $(n=15,455)$. Among the 37 studies that informed the diagnostic method for active tuberculosis, $73 \%$ confirmed tuberculosis bacteriologically.

Six per cent of studies involved hospitalised populations $(n=4)$. In these studies, overestimation of the prevalence is likely. Three studies $[33,50,55]$ reported only active tuberculosis prevalence, and one described both active and latent tuberculosis [43]. None of them entered the meta-analyses. 


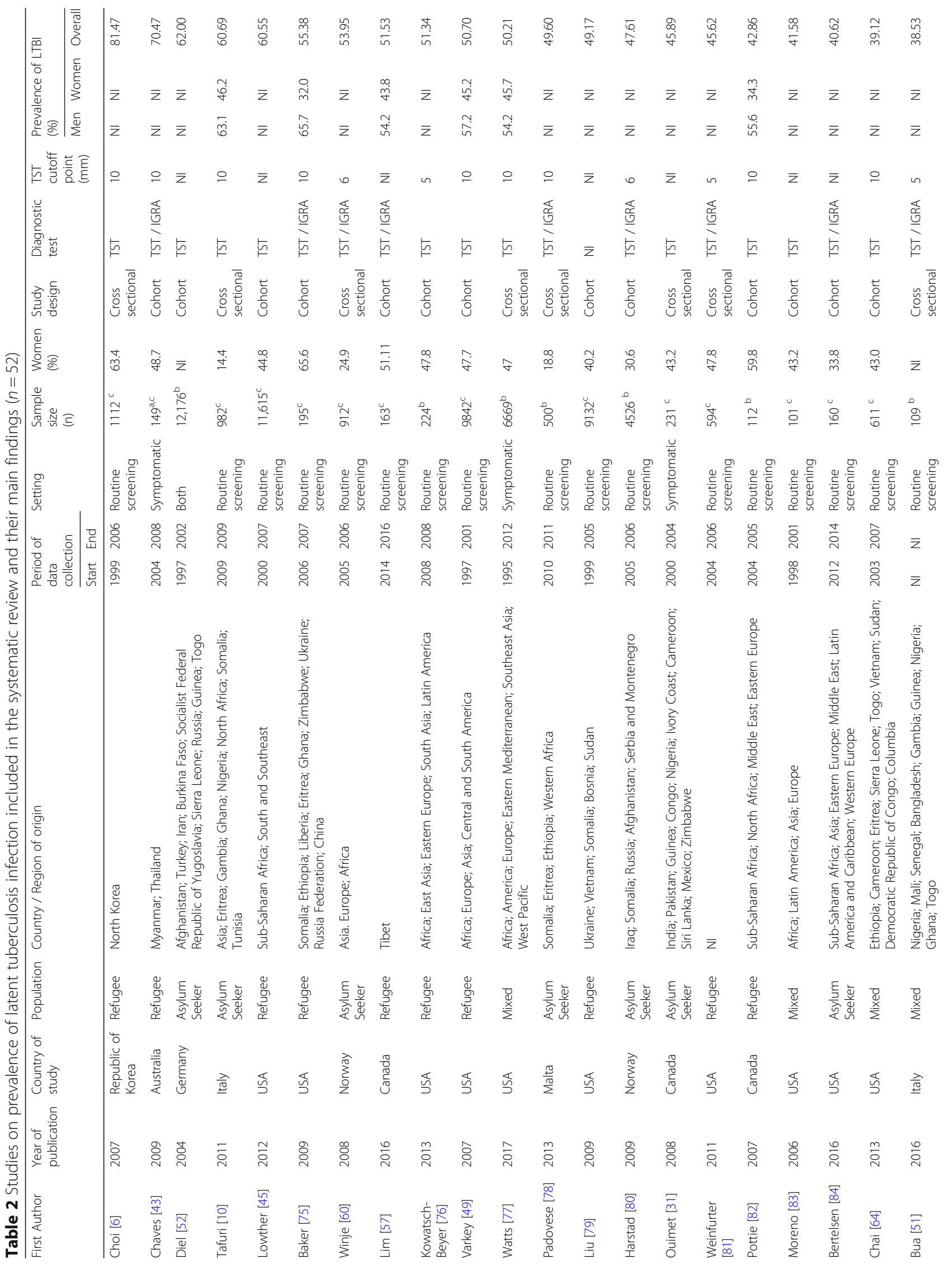




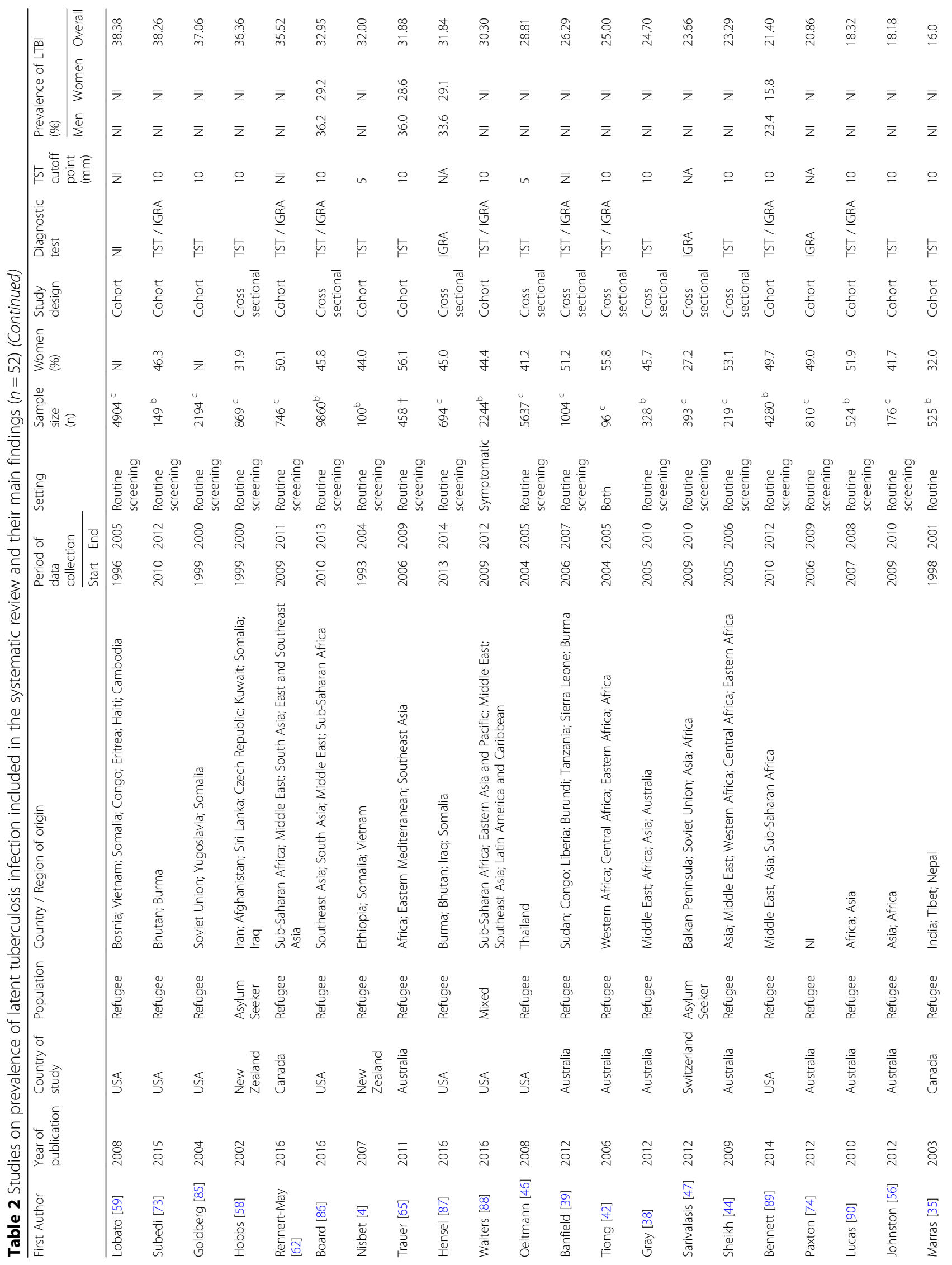




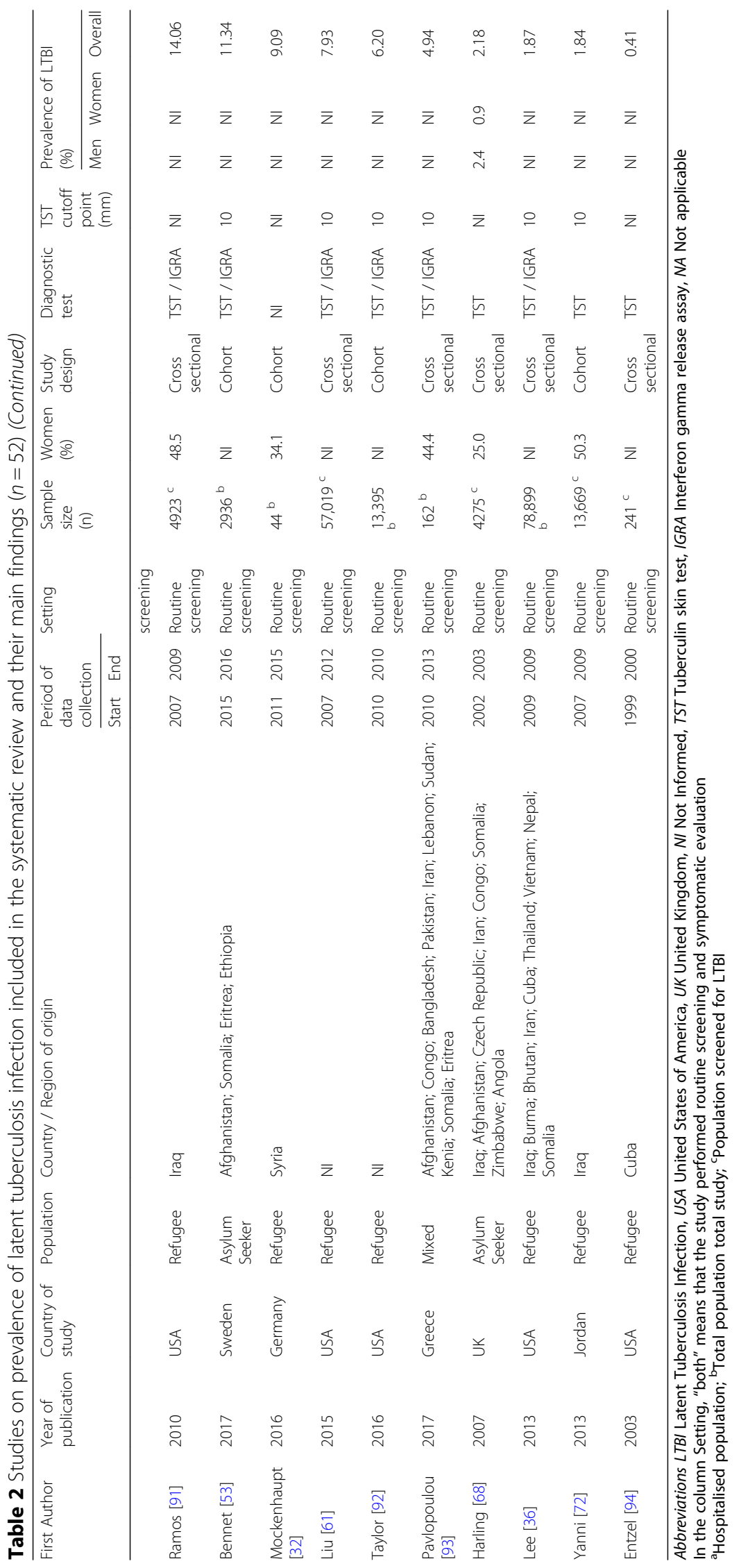




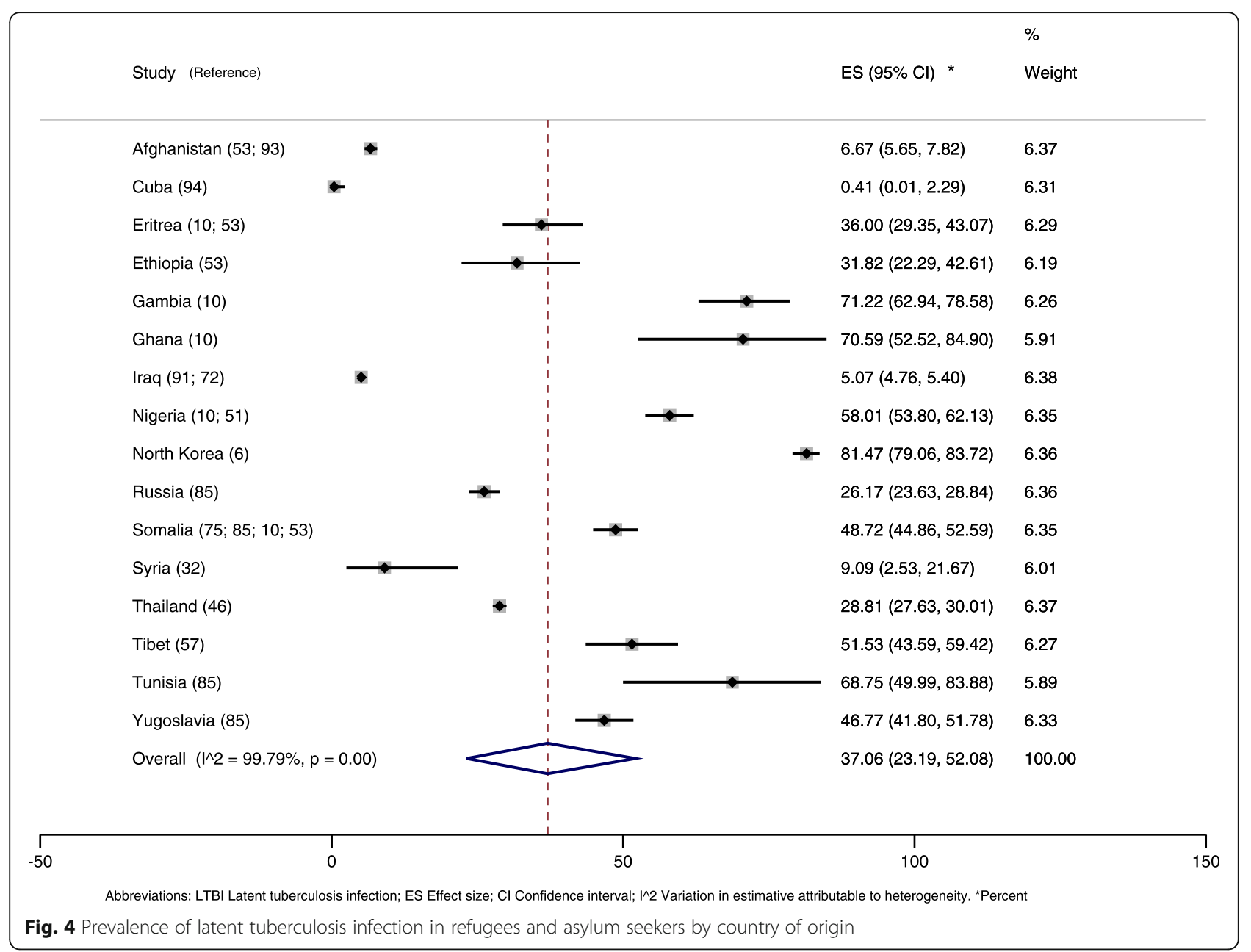

Finally, only 15 articles used the 1951 United Nations Convention or a very similar definition of refugee and asylum seeker.

\section{Discussion}

This systematic review and meta-analysis on tuberculosis prevalence in refugees identified 67 studies with a total of 599,072 evaluated individuals, of whom nearly half were evaluated for LTBI. The main finding was the high prevalence of active tuberculosis in these populations. Although some studies involving hospitalised populations may have overestimated the prevalence of the disease, most of the studies were conducted as routine screening in symptom-free individuals. The lower positive predictive value in symptom-free individuals may also result in overestimation of the prevalence, but despite these possible risks of bias, the prevalence is high.

Prevalence rates found in the current study, albeit very heterogeneous, were comparable to other very-high risk groups, such as prisoners and homeless [95, 96]. Although the highest prevalence rates were found in
Syrians and among those who migrated to the Americas, these figures are based, respectively, on one and two studies solely. Furthermore, the results among Syrians refugees are from a highly selected setting and are based on a small sample: 5 among 44 hospitalised patients. Yet, this finding is worth highlighting: between 1990 and 2011 the tuberculosis prevalence in Syria had decreased from 85 to 23/100,000 [97]. Armed conflicts and wars destroy the basic medical infrastructure, undermine health agendas and cause significant shortages of health professionals and medicines, leading the prevalence of tuberculosis to a possible underestimation $[8,97]$. Symptoms of the active phase of tuberculosis, such as coughing and fatigue, may go unnoticed to already infected individuals and health care workers in crisis settings, because they are insidious [17]. Dangerous situations encountered during migration, including overcrowding, incarceration, malnutrition, challenges to access health care, low adherence to treatment, associated risk of HIV infection and exposure to other migrants from higher incidence countries also contribute to the risk of 


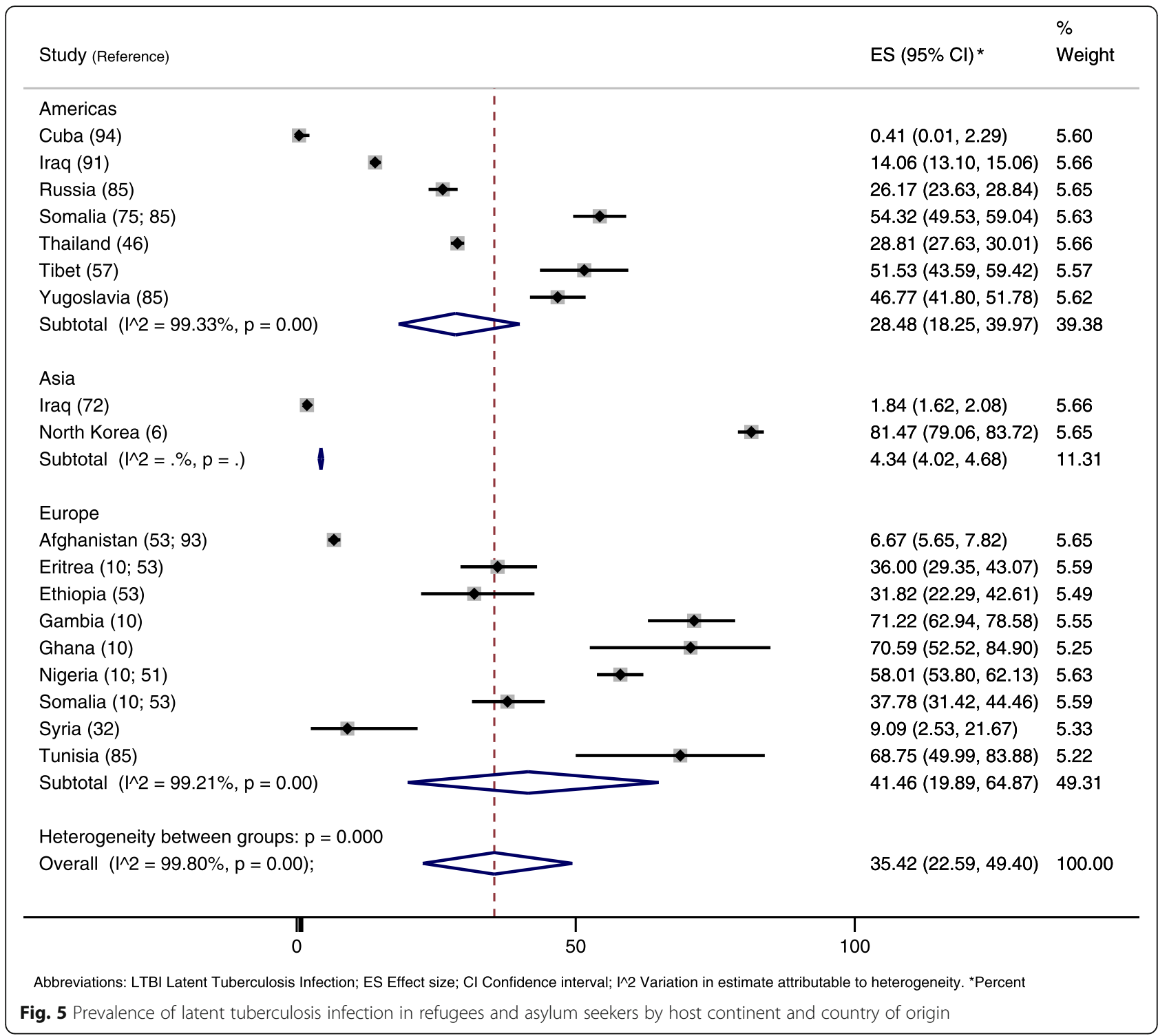

contamination by $M$. tuberculosis and progression to disease [8, 97-99].

In regard to latent tuberculosis infection (LTBI), reported prevalence rates were also high, similar to those observed in populations characterised by high vulnerability to infection, such as prisoners [100], when compared to the overall population, in whom LTBI is expected to be $23 \%$ [14]. The exception was a study in children, an expected finding, as LTBI prevalence increases with age. LTBI prevalence was the highest among Somali refugees, in particular those who migrated to the Americas, in spite of possible underestimation due to exclusion of those with the highest probability of a false negative test result (immunosuppressed persons) in one of the two studies. The difference may reflect true heterogeneity in the populations migrating to these continents but could also reflect different methods of screening (TST cut-off, TST versus IGRA versus TST and IGRA) or targeted populations for screening in both continents. Alternatively, it could reflect differences in methodology regarding targeted population or testing criteria, but we did not find such differences. We cannot discard differences due to the choice of the continent of destiny or the journey itself, but this hypothesis remains speculative. Again, albeit based on few studies and the possible biases, the finding is noteworthy. Somalia is one of the poorest countries in the world and has also been facing a civil war in the Horn of Africa.

Despite the few studies per country of origin and per host continent, which limits the analysis according to these variables, and in spite of the heterogeneous populations involved, the high overall rates of active and latent tuberculosis found in the present review emphasise 
the responsibility of host countries to meet refugees' specific health needs and of the global health community to fight tuberculosis in low-income countries from where most refugees flee, in order to attain WHO's End Tuberculosis Strategy to eliminate the disease by 2050 [18]. In the host countries, there are still many challenges that need to be overcome for better care of refugees, such as lack of training of professionals, fear of breaches of confidentiality, fear of stigma and social rejection due to illness, fear of consequences in the immigration process due to the diagnosis of disease, insufficient information on the screening and treatment process, difficulty in communicating due to language differences, among others [23].

To the best of our knowledge, this is the first summarised analysis of tuberculosis among this specific subpopulation of migrants, and the first to include average measures according to their origin and destination. Among this review strengths is the reporting quality of most studies. In regard to bias, active tuberculosis was bacteriologically confirmed, and almost all derived from routine screening. These characteristics reduce the likelihood of overestimation.

Nonetheless, reported prevalence rates may be overestimated among symptomatic individuals in health facilities such as hospitals. Also, studies in populations applying for visa in countries with health restrictions may have underestimated prevalence of LTBI, since those known to be positive may give up application.

Moreover, this is a very heterogeneous group of individuals, and attempts to summarise any measure are challenging. The definition of "refugee" or "asylum seekers" was not clear in all studies. Age groups were highly heterogeneous as well, and prevalence of LTBI increases with age, thus influencing findings; in addition, language difficulties, fear of immigration authorities, lack of awareness of symptoms and fear of stigma may reduce the efficacy of tuberculosis detection mechanisms [8].

Origin and destination may reflect socio-economic status, reasons for fleeing, and tuberculosis setting, which explains our choice for meta-analyses. However, many studies could not be included in the meta-analyses due to lack of information about the country of origin. Thus, because only a few studies were eligible, all had to be included regardless of their quality. Some findings included in the meta-analyses refer to one or two studies only. Meta-regression could not be performed due to information gaps regarding study populations (e.g., gender, age, follow-up).

Additionally, most studies were performed in developed countries, and thus do not represent the majority of current refugees, who are hosted in low- and medium-income countries [101]. Generalizability and assertive conclusions are thus restricted. Lastly, although our bibliographic searches were finalised in August
2017, recent waves of forced migration are not entirely covered, because several studies refer to data collected up to 2011. More efforts and funds should be dedicated to international cooperation studies on tuberculosis and other health issues - among forced migrants [102].

\section{Conclusion}

Despite the highly heterogeneous prevalence across countries, active and latent tuberculosis seem to be frequent health issues among refugees and asylum seekers. Rapid screening is necessary in order to allow early detection and prompt treatment - or prevention - of the disease. This policy should aim at their protection against the disease, rather than their exclusion and discrimination. Efforts to guarantee their right to adequate health care cannot be overemphasised.

\section{Supplementary information}

Supplementary information accompanies this paper at https://doi.org/10. 1186/s12889-020-08907-y.

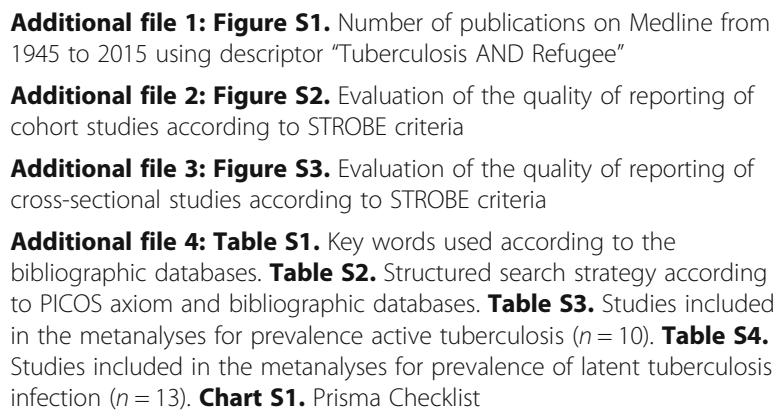

Additional file 2: Figure S2. Evaluation of the quality of reporting of cohort studies according to STROBE criteria

Additional file 3: Figure S3. Evaluation of the quality of reporting of cross-sectional studies according to STROBE criteria

Additional file 4: Table S1. Key words used according to the bibliographic databases. Table S2. Structured search strategy according to PICOS axiom and bibliographic databases. Table S3. Studies included in the metanalyses for prevalence active tuberculosis $(n=10)$. Table S4. Studies included in the metanalyses for prevalence of latent tuberculosis infection $(n=13)$. Chart S1. Prisma Checklist

\section{Abbreviations}

$\mathrm{Cl}$ : Confidence intervals; HIV: Human immunodeficiency virus; IGRA: Interferon-gamma release assays; LTBI: Latent tuberculosis infection; PRISMA: Preferred Reporting Items for Systematic Reviews and MetaAnalyses; STROBE: Strengthening the Reporting of Observational Studies in Epidemiology; TST: Tuberculin skin testing; $I^{2}$ : Variation in estimative attributable to heterogeneity

\section{Acknowledgements}

Not applicable.

\section{Authors' contributions}

RP and FMS searched, selected and extracted the data. RP also contacted the author of relevant studies. MLB and AT were the third and fourth reviewers for study selection and data extraction. RP, FMS, AT and EF established the inclusion criteria, analysed and interpreted the data. RP, FMS and AT wrote the first manuscript draft. RC and JUB performed overall and subgroup meta-analyses and graphs. AT and EF supervised the study and with JUB and RC, critically reviewed the report. All authors read, made contributions and approved the final manuscript.

\section{Funding}

This study was financed in part by the Coordenação de Aperfeiçoamento de Pessoal de Nível Superior - Brasil (CAPES) - Finance Code 001. CAPES had no role in the constructions, analysis or writing of this manuscript.

Availability of data and materials

All data generated or analysed during this study are included in this published article [and its supplementary information files]. 


\section{Ethics approval and consent to participate}

The study consists of a published literature review analysis; thus, no ethical approval was necessary.

\section{Consent for publication}

\author{
Not applicable.
}

\section{Competing interests}

The corresponding author is a member of the editorial board of this journal. The other authors declare that they have no competing interests.

\section{Author details}

${ }^{1}$ State University of Rio de Janeiro, Rio de Janeiro, RJ, Brazil. ${ }^{2}$ Oswaldo Cruz Foundation, Rio de Janeiro, RJ, Brazil. ${ }^{3}$ McGill University, Montreal, QC, Canada. ${ }^{4}$ Federal University of Rio de Janeiro, Rio de Janeiro, RJ, Brazil.

Received: 20 October 2019 Accepted: 12 May 2020

Published online: 03 June 2020

\section{References}

1. United Nations High Commissioner For Refugees. Global Trends: Forced Displacement in 2018. Geneva: UNHCR; 2019. Available at https://www. unhcr.org/5d08d7ee7.pdf. Assessed 18 May 2020

2. The United Nations High Commissioner for Refugees. Convention and protocol relating to the status of refugees. Geneva: UNHCR; 1951. Available at https://www.unhcr.org/3b66c2aa10. Assessed 18 May 2020.

3. United Nations High Commissioner For Refugees. Refugee Protection and International Migration. Geneva: UNHCR; 2007. Available at https://www. unhcr.org/protection/migration/4a24ef0ca2/unhcr-refugee-protectioninternational-migration.html. Assessed 18 May 2020.

4. Nisbet SM, et al. Good outcome in HIV-infected refugees after resettlement in New Zealand: population study. Intern Med J. 2007;37(5):290-4.

5. Walker $\mathrm{P}$, Jaranson J. Refugee and immigrant health care. Med Clin North Am. 1999;83:1103-20.

6. Choi CM, et al. Tuberculosis among dislocated north Koreans entering Republic of Korea since 1999. J Korean Med Sci. 2007;22(6):963-7.

7. Zimmerman C, et al. Migration and health: a framework for 21st century policy-making. PLoS Med. 2011;8(5):e1001034.

8. Dhavan $\mathrm{P}$, et al. An overview of tuberculosis and migration. Int J Tuberc Lung Dis. 2017;21(6):610-23.

9. Gavagan T, Brodyaga L. Medical care for immigrants and refugees. Am Fam Physician. 1998;57(5):1061-8.

10. Tafuri $\mathrm{S}$, et al. Tuberculosis screening in migrant reception centers: results of a 2009 Italian survey. Am J Infect Control. 2011:39(6):495-9.

11. Toole M, Waldman R. Refugees and displaced persons: war, hunger, and public health. JAMA. 1993:270(5):600-5.

12. World Health Organization. Tuberculosis care and control in refugee and displaced populations: an interagency field manual. 2nd ed; 2007.

13. World Health Organization. WHO | Global tuberculosis report 2019. Geneva: WHO Library Cataloguing-in-Publication; 2019. Available at http://www.who. int/tb/publications/global_report/en/. Assessed 18 May 2020.

14. Houben R, Dodd P. The global burden of latent tuberculosis infection: a reestimation using mathematical Modelling. PLoS Med. 2016;13:10.

15. Centers For Disease Control And Prevention. Basic TB facts. Atlanta: Centers for Disease Control and Prevention; 2012.

16. Beggs $C B$, et al. The transmission of tuberculosis in confined spaces: an analytical review of alternative epidemiological models. Int J Tuberc Lung Dis. 2003;7(11):1015-26.

17. Kimbrough W, et al. The burden of tuberculosis in crisis-affected populations: a systematic review. Lancet Infect Dis. 2012;12(12):950-65.

18. World Health Organization. The End TB Strategy. Geneva: World Health Organization; 2015. Available at https://www.who.int/tb/strategy/end-tb/en/. Assessed 18 May 2020.

19. Pareek $M$, et al. The impact of migration on tuberculosis epidemiology and control in high-income countries: a review. BMC Med. 2016;14:48.

20. Arshad $\mathrm{S}$, et al. Active screening at entry for tuberculosis among new immigrants: a systematic review and meta-analysis. Eur Respir J. 2010;35(6): 1336-45.

21. Faerstein E, Trajman A. Forced migration and health: problems and responses. In: Parker R, García J, editors. Routledge Handbook on the Politics of Global Health, vol. 1. 1st ed. Londres: Routledge; 2019. p. 359-67.
22. Eiset $\mathrm{AH}$, Wejse $\mathrm{C}$. Review of infectious diseases in refugees and asylum seekers-current status and going forward. Public Health Rev. 2017;38:22.

23. Seedat $F$, et al. How effective are approaches to migrant screening for infectious diseases in Europe? A systematic review. Lancet Infect Dis. 2018; 18(9):e259-71.

24. Klinkenberg $E$, et al. Migrant tuberculosis screening in the EU/EEA: yield, coverage and limitations. Eur Respir J. 2009;34(5):1180-9.

25. Bozorgmehr $\mathrm{K}$, et al. Yield of active screening for tuberculosis among asylum seekers in Germany: a systematic review and meta-analysis. Eurosurveillance. 2017;22(12):30491.

26. Clark RC, Mytton J. Estimating infectious disease in UK asylum seekers and refugees: a systematic review of prevalence studies. J Public Health Oxf Engl. 2007;29(4):420-8.

27. Gilpin C, et al. The World Health Organization standards for tuberculosis care and management. Eur Resp J. 2018;51:1800098.

28. Von Elm E, et al. The strengthening the reporting of observational studies in epidemiology (STROBE)statement: guidelines for reporting observational studies. Lancet. 2007;370(9596):1453-7.

29. StataCorp. Stata Statistical Software: Release 13. College Station: StataCorp LP; 2013.

30. Moher $\mathrm{D}$, et al. Preferred reporting items for systematic reviews and metaanalyses: the PRISMA statement. Ann Intern Med. 2009;4(151):264-9.

31. Ouimet MJ, et al. Current pathologies in Montreal's asylum seekers. Can J Public Health Rev Can Sante Publique. 2008;99(6):499-504.

32. Mockenhaupt FP, et al. Profile of illness in Syrian refugees: A GeoSentinel analysis, 2013 to 2015. Euro Surveill. 2016;21(10):1-5.

33. Ravensbergen $\mathrm{SJ}$, et al. High prevalence of infectious diseases and drugresistant microorganisms in asylum seekers admitted to hospital; no Carbapenemase producing Enterobacteriaceae until September 2015. PLoS One. 2016;11(5):e0154791.

34. Rajamanoharan S, et al. Genitourinary medicine/HIV services for persons with insecure immigration or seeking asylum in the United Kingdom: a British co-operative clinical group survey. Int J STD AIDS. 2004;15(8):509-14.

35. Marras TK, et al. Tuberculosis among Tibetan refugee claimants in Toronto: 1998 to 2000. Chest. 2003;124(3):915-21.

36. Lee $D$, et al. Disease surveillance among newly arriving refugees and immigrants--electronic disease notification system, United States, 2009. MMWR Surveill Summ. 2013;62(7):1-20.

37. LoBue PA, Moser KS. Screening of immigrants and refugees for pulmonary tuberculosis in San Diego County, California. Chest. 2004;126(6):1777-82.

38. Gray $\mathrm{K}$, et al. Vitamin $\mathrm{d}$ and tuberculosis status in refugee children. Pediatr Infect J. 2012;31(5):521-3.

39. Banfield $S$, et al. Factors associated with the performance of a blood-based interferon- $\gamma$ release assay in diagnosing tuberculosis. PLoS One. 2012;7(6): e38556.

40. Otoukesh $\mathrm{S}$, et al. A retrospective study of demographic parameters and major health referrals among afghan refugees in Iran. Int J Equity Health. 2012;11:7.

41. Dierberg $\mathrm{KL}$, et al. Improved detection of tuberculosis and multidrugresistant tuberculosis among Tibetan refugees, India. Emerg Infect Dis. 2016; 22(3):463-8.

42. Tiong $A C$, et al. Health issues in newly arrived African refugees attending general practice clinics in Melbourne. Med J Aust. 2006;185(11-12):602-6.

43. Chaves NJ, et al. Screening practices for infectious diseases among Burmese refugees in Australia. Emerg Infect Dis. 2009;15(11):1769-72.

44. Sheikh $\mathrm{M}$, et al. The epidemiology of health conditions of newly arrived refugee children: a review of patients attending a specialist health clinic in Sydney. J Paediatr Child Health. 2009:45(9):509-13.

45. Lowther SA, et al. HIV/AIDS and associated conditions among HIV-infected refugees in Minnesota, 2000-2007. Int J Env Res Public Health. 2012;9(11): 4197-209.

46. Oeltmann JE, et al. Multidrug-resistant tuberculosis outbreak among US-bound Hmong refugees, Thailand, 2005. Emerg Infect Dis. 2008;14(11):1715-21.

47. Sarivalasis A, et al. Factors associated with latent tuberculosis among asylum seekers in Switzerland: a cross-sectional study in Vaud County. BMC Infect Dis. 2012;12:285.

48. Harstad I, et al. The role of entry screening in case finding of tuberculosis among asylum seekers in Norway. BMC Public Health. 2010;10:670.

49. Varkey $P$, et al. The epidemiology of tuberculosis among primary refugee arrivals in Minnesota between 1997 and 2001. J Travel Med. 2007;14(1):1-8. 
50. Soydan $L$, et al. Frequency of abnormal pulmonary computed tomography findings in asylum seeking refugees in Turkey. Int Health. 2017;9(2):118-23.

51. Bua A, et al. Tuberculosis screening among asylum seekers in Sardinia. J Public Health. 2016;38(4):760-4

52. Diel $R$, et al. Molecular epidemiology of tuberculosis among immigrants in Hamburg, Germany. J Clin Microbiol. 2004;42(7):2952-60.

53. Bennet R, Eriksson M. Tuberculosis infection and disease in the 2015 cohort of unaccompanied minors seeking asylum in northern Stockholm, Sweden. Infect Dis. 2017;49(7):501-6.

54. Russo G, et al. Health profile and disease determinants among asylum seekers: a cross-sectional retrospective study from an Italian reception Centre. J Public Health. 2016;38(2):212-22.

55. Lalchandani $S$, et al. Obstetric profiles and pregnancy outcomes of immigrant women with refugee status. Ir Med J. 2001;94(3):79-80.

56. Johnston $V$, et al. The health of newly arrived refugees to the top end of Australia: results of a clinical audit at the Darwin refugee health service. Aust J Prim Health. 2012;18(3):242-7.

57. Lim $\mathrm{R}$, et al. Is universal screening necessary? Incidence of tuberculosis among Tibetan refugees arriving in Calgary, Alberta. Can Respir J. 2016;2016: 8249843.

58. Hobbs M, et al. The health status of asylum seekers screened by Auckland public health in 1999 and 2000. N Z Med J. 2002;115(1160):U152.

59. Lobato $\mathrm{MN}$, et al. Tuberculosis in a low-incidence US area: local consequences of global disruptions. Int J Tuberc Lung Dis. 2008;12(5):506-12.

60. Winje BA, et al. Screening for tuberculosis infection among newly arrived asylum seekers: comparison of QuantiFERONTB gold with tuberculin skin test. BMC Infect Dis. 2008;8:65.

61. Liu Y, et al. Effect of a culture-based screening algorithm on tuberculosis incidence in immigrants and refugees bound for the United States: a population-based cross-sectional study. Ann Intern Med. 2015;162(6):420-8.

62. Rennert-May E, et al. A step toward tuberculosis elimination in a lowincidence country: successful diagnosis and treatment of latent tuberculosis infection in a refugee clinic. Can Respir J. 2016;2016:7980869.

63. Sane Schepisi $M$, et al. Tuberculosis case finding based on symptom screening among immigrants, refugees and asylum seekers in Rome. BMC Public Health. 2013;13:872.

64. Chai SJ, et al. Infectious disease burden and vaccination needs among asylees versus refugees, District of Columbia. Clin Infect Dis. 2013;56(5):652-8.

65. Trauer JM, Krause VL. Assessment and management of latent tuberculosis infection in a refugee population in the Northern Territory. Med J Aust. 2011;194(11):579-82.

66. Gibson-Helm ME, et al. Maternal health and pregnancy outcomes comparing migrant women born in humanitarian and nonhumanitarian source countries: a retrospective, observational study. Birth. 2015;42(2):116-24.

67. Schneeberger Geisler S, et al. Screening for tuberculosis in asylum seekers: comparison of chest radiography with an interview-based system. Int J Tuberc Lung Dis. 2010;14(11):1388-94.

68. Harling $\mathrm{R}$, et al. Tuberculosis screening of asylum seekers: 1 years' experience at the Dover induction Centres. Public Health. 2007;121(11):822-7.

69. Meier $V$, et al. Tuberculosis in newly arrived asylum seekers: a prospective 12 month surveillance study at Friedland, Germany. Int J Hyg Env Health. 2016; 219(8):811-5.

70. Bloch-Infanger $C$, et al. Increasing prevalence of infectious diseases in asylum seekers at a tertiary care hospital in Switzerland. PLoS One. 2017; 12(6):e0179537.

71. Weinrich JM, et al. Yield of chest X-ray tuberculosis screening of immigrants during the European refugee crisis of 2015: a single-Centre experience. Eur Radiol. 2017;27(8):3244-8

72. Yanni EA, et al. The health profile and chronic diseases comorbidities of USbound Iraqi refugees screened by the International Organization for Migration in Jordan: 2007-2009. J Immigr Minor Health. 2013;15(1):1-9.

73. Subedi $P$, et al. Evaluation of latent tuberculous infection and treatment completion for refugees in Philadelphia, PA, 2010-2012. Int J Tuberc Lung Dis. 2015;19(5):565-9.

74. Paxton GA, et al. Post-arrival health screening in Karen refugees in Australia. PLoS One. 2012;7(5):e38194.

75. Baker CA, et al. Serial testing of refugees for latent tuberculosis using the QuantiFERON-gold in-tube: effects of an antecedent tuberculin skin test. Am J Trop Med Hyg. 2009;80(4):628-33.
76. Kowatsch-Beyer K, et al. Utilization of a latent tuberculosis infection referral system by newly resettled refugees in Central Ohio. Int J Tuberc Lung Dis. 2013;17(3):320-5.

77. Watts NS, et al. Association between parasitic infections and tuberculin skin test results in refugees. Travel Med Infect Dis. 2017;16:35-40.

78. Padovese $V$, et al. Prevalence of latent tuberculosis, syphilis, hepatitis B and C among asylum seekers in Malta. J Public Health. 2014;36(1):22-7.

79. Liu Y, et al. Overseas screening for tuberculosis in U.S.-bound immigrants and refugees. N Engl J Med. 2009;360(23):2406-15.

80. Harstad I, et al. Tuberculosis screening and follow-up of asylum seekers in Norway: a cohort study. BMC Public Health. 2009:9:141.

81. Weinfurter $P$, et al. Predictors of discordant tuberculin skin test and QuantiFERON(R)-TB gold in-tube results in various high-risk groups. Int J Tuberc Lung Dis. 2011;15(8):1056-61.

82. Pottie K, et al. Prevalence of selected preventable and treatable diseases among government-assisted refugees: implications for primary care providers. Can Fam Physician. 2007;53(11):1928-34.

83. Moreno A, et al. Characteristics and utilization of primary care services in a torture rehabilitation center. J Immigr Minor Health. 2006;8(2):163-71.

84. Bertelsen NS, et al. Primary care screening methods and outcomes for asylum seekers in New York City. J Immigr Minor Health. 2018;20(1):171-7.

85. Goldberg SV, et al. Cultural case management of latent tuberculosis infection. Int J Tuberc Lung Dis. 2004;8(1):76-82.

86. Board AR, Suzuki S. The interrelation between intestinal parasites and latent TB infections among newly resettled refugees in Texas. Int Health. 2016;8(1):67-72

87. Hensel RL, et al. Increased risk of latent tuberculous infection among persons with pre-diabetes and diabetes mellitus. Int J Tuberc Lung Dis. 2016;20(1):71-8

88. Walters JK, Sullivan AD. Impact of routine Quantiferon testing on latent tuberculosis diagnosis and treatment in refugees in Multnomah County, Oregon, November 2009-October 2012. J Immigr Minor Health. 2016;18(2):292-300.

89. Bennett RJ, et al. Prevalence and treatment of latent tuberculosis infection among newly arrived refugees in San Diego County, January 2010-October 2012. Am J Public Health. 2014;104(4):e95-102.

90. Lucas $\mathrm{M}$, et al. A prospective large-scale study of methods for the detection of latent mycobacterium tuberculosis infection in refugee children. Thorax. 2010;65(5):442-8.

91. Ramos M, Orozovich P, Moser K, Phares CR, Stauffer W, Mitchell T. Health of resettled Iraqi refugees - San Diego County, California, October 2007September 2009. Morb Mortal Wkly Rep. 2010;59(49):1614-8.

92. Taylor EM, et al. Latent tuberculosis infection among immigrant and refugee children arriving in the United States: 2010. J Immigr Minor Health. 2016;18(5):966-70.

93. Pavlopoulou ID, et al. Clinical and laboratory evaluation of new immigrant and refugee children arriving in Greece. BMC Pediatr. 2017;17(1):132.

94. Entzel PP, et al. The health status of newly arrived refugee children in Miami-Dade County, Florida. Am J Public Health. 2003;93(2):286-8.

95. Fazel S, Baillargeon J. The health of prisoners. Lancet. 2011;377(9769):956-65.

96. Beijer $U$, et al. Prevalence of tuberculosis, hepatitis $C$ virus, and HIV in homeless people: a systematic review and meta-analysis. Lancet Infect Dis. 2012;12(11):859-70.

97. Ismail M, et al. Tuberculosis, war, and refugees: spotlight on the Syrian humanitarian crisis. PLoS Pathog. 2018;14(6):e1007014.

98. Lonnroth $\mathrm{K}$, et al. Tuberculosis in migrants in low-incidence countries: epidemiology and intervention entry points. Int J Tuberc Lung Dis. 2017; 21(6):624-37.

99. de Vries SG, et al. Barriers and facilitators to the uptake of tuberculosis diagnostic and treatment services by hard-to-reach populations in countries of low and medium tuberculosis incidence: a systematic review of qualitative literature. Lancet Infect Dis. 2017;17(5):e128-43.

100. de Navarro PD, et al. Prevalence of latent mycobacterium tuberculosis infection in prisoners. J Bras Pneumol. 2016;42(5):348-55.

101. Abubakar I, et al. The UCL-Lancet Commission on Migration and Health: the health of a world on the move. Lancet. 2018;392(10164):2606-54.

102. Shete $P B$, et al. Defining a migrant-inclusive tuberculosis research agenda to end TB. Int J Tuberc Lung Dis. 2018;22(8):835-43.

\section{Publisher's Note}

Springer Nature remains neutral with regard to jurisdictional claims in published maps and institutional affiliations. 